\title{
Seleção Assistida por Marcadores Moleculares Visando ao Desenvolvimento de Plantas Resistentes a Doenças, com Ênfase em Feijoeiro e Soja
}

\author{
Ana Lilia Alzate-Marin', Gerardo D. L. Cervigni ${ }^{1}$, Maurilio A. Moreira ${ }^{1,2}$ \& Everaldo G. Barros ${ }^{1,3}$ \\ ${ }^{1}$ Instituto de Biotecnologia Aplicada à Agropecuária - BIOAGRO; ${ }^{2}$ Departamento de Bioquímica e Biologia \\ Molecular; ${ }^{3}$ Departamento de Biologia Geral; Universidade Federal de Viçosa, CEP 36571-000, Viçosa, MG, \\ fax (31) 3899-2864, e-mail: ebarros@ufv.br
}

(Aceito para publicação em 16/02/2005)

Autor para correspondência: Everaldo G. de Barros

ALZATE-MARIN, A.L., CERVIGNI, G.D.L., MOREIRA, M.A. \& BARROS, E.G. Seleção assistida por marcadores moleculares visando ao desenvolvimento de plantas resistentes a doenças, com ênfase em feijoeiro e soja. Fitopatologia Brasileira 30:333-342. 2005.

\begin{abstract}
RESUMO
A transferência de alelos de resistência a doenças em plantas pode ser facilitada pelo uso de marcadores moleculares do DNA. Se proximamente ligados a alelos de resistência, eles podem ser usados na seleção assistida por marcadores (S.A.M.). Uma aplicação concreta dos marcadores na S.A.M. é durante o processo de piramidação de alelos de resistência. Por meio da S.A.M., em três gerações de retrocruzamento, o Programa de Melhoramento do Feijoeiro do BIOAGRO, Universidade Federal de Viçosa (Minas Gerais, Brasil), obteve linhagens de feijoeiro (Phaseolus vulgaris) com características fenotípicas similares às da cultivar Rudá (recorrente), contendo alelos de resistência à antracnose, ferrugem e manchaangular. No momento, sementes das linhagens $\mathrm{RC}_{3} \mathrm{~F}_{4}$, homozigotas para os locos de resistência estão sendo multiplicadas para serem submetidas a inoculações com os patógenos de interesse e a testes agronômicos. O Programa de Melhoramento da Qualidade da Soja do BIOAGRO vem usando marcadores moleculares para identificar "quantitative trait loci" (QTLs) associados à resistência ao nematóide de cisto da soja (NCS). Foram identificados dois marcadores microssatélites (Satt038 e Satt163) flanquendo o alelo de resistência $r h g 1$ e também marcadores ligados a um QTL que confere resistência à raça 14 do NCS. Esse QTL explica mais de 40\% da resistência da soja (Glycine max) cultivar Hartwig, uma das principais fontes de resistência ao NCS. A S.A.M. é uma realidade em diversos programas de melhoramento no mundo inteiro que visam ao desenvolvimento de cultivares resistentes a doenças. O seu uso efetivo no melhoramento depende de uma maior sintonia entre o melhorista e o biólogo molecular de plantas.
\end{abstract}

Palavras-chaves adicionais: melhoramento de plantas, piramidação, culturas anuais, Glycine max, Phaseolus vulgaris.

\begin{abstract}
Marker assisted selection in the development of disease resistant plants, with emphasis on common bean and soybean

Transfer of disease resistance alleles in plants can be expedited by the use of DNA molecular markers. If the markers are tightly linked to the resistance alleles they can be used for marker assisted selection (M.A.S.). One effective use of M.A.S. is found in the process of pyramiding resistance alleles. By using M.A.S., in three backcross generations, the Bean Breeding Program of BIOAGRO, Federal University of Viçosa (Minas Gerais, Brazil), has obtained bean (Phaseolus vulgaris) lines phenotypically similar to cultivar Rudá (recurrent) and resistant to anthracnose, rust and angular leaf spot. Seeds of $\mathrm{BC}_{3} \mathrm{~F}_{4}$ lines currently are being multiplied to undergo inoculation with specific pathogens and agronomic performance tests. The Soybean Quality Breeding program of BIOAGRO used molecular markers to identify quantitative trait loci (QTLs) associated with resistance to soybean cyst nematode (SCN). Two microsattelite markers (Satt038 and Satt163) flanking the allele rhgl were identified. Markers linked to a QTL that confers resistance to SCN race 14 were also identified. This QTL explains more than $40 \%$ of the resistance present in soybean (Glycine max) cultivar Hartwig, one of the most import resistance sources for SCN. The use of M.A.S. is a reality in several breeding programs around the that are trying to develop disease resistant cultivars. The effective use of this tool depends on a greater understanding between the breeder and the plant molecular biologist.

Additional keywords: plant breeding, gene pyramiding, annual crops, Glycine max, Phaseolus vulgaris.
\end{abstract}

\section{INTRODUÇÃO}

Os avanços da genética e epidemiologia têm proporcionado melhor entendimento das interações planta-patógeno, ficando evidente que esse tipo de relação envolve fatores genéticos de ataque e de defesa presentes no patógeno e no hospedeiro, respectivamente, sob a influência do ambiente (Flor, 1971). Em muitos casos, como nos patossistemas 
Cladosporium fulvum Cooke - tomateiro (Lycopersicon esculentum Mill.) e Uromyces appendiculatus (Pers.) Unger var. appendiculatus - feijoeiro (Phaseolus vulgaris L.), a resistência é determinada por poucos genes que apresentam herança simples. No entanto, esta não é a regra. A resistência é, na maioria das vezes, poligênica ou de caráter quantitativo, normalmente envolvendo uma série de genes, com efeitos diferenciados, associados a um pronunciado efeito do ambiente, o que leva a uma variação fenotípica contínua na reação do hospedeiro.

No manejo integrado de doenças e pragas, uma das estratégias preconizadas é o uso de cultivares resistentes. Estas normalmente são desenvolvidas pela transferência de alelos de resistência de fontes exóticas e, muitas vezes, não adaptadas, para cultivares elite. Essa estratégia vem sendo usada com sucesso, em programas de melhoramento, há várias décadas. Devido à co-evolução entre hospedeiro e patógeno e o conseqüente surgimento de novas raças, cultivares resistentes necessitam ser continuamente desenvolvidas. Essa é uma situação que faz parte da dinâmica da interação planta-patógeno e que precisa ser compreendida pelo melhorista.

No processo de transferência de alelos de resistência, os marcadores moleculares do DNA podem ser uma ferramenta bastante útil. Esses marcadores, se estreitamente ligados aos alelos de resistência, podem ser usados na seleção assistida por marcadores (S.A.M.), particularmente nas etapas iniciais e intermediárias do melhoramento. Nas etapas finais, as inoculações ou exposição da planta ao patógeno em condições de campo são imprescindíveis para confirmar a seleção indireta feita inicialmente por meio dos marcadores.

Os marcadores moleculares são úteis, também, se levarmos em conta que durante o melhoramento, via de regra, são monitorados diversos tipos de genes, não somente aqueles envolvidos com a resistência. Nesse contexto, é interessante dispor de uma ferramenta de seleção que possa ser utilizada de modo direto, pela simples análise da presença ou ausência de uma seqüência de DNA nas folhas das plantas que estão sendo melhoradas.

O uso de marcadores moleculares é também justificado em situações em que o fenótipo é de difícil mensuração. É o caso da resistência a nematóides, que é determinada pelo exame direto de cistos na raiz. Resistência a nematóide foi uma das primeiras características associadas a um marcador molecular (Rick \& Fobes, 1974).

Uma outra aplicação bastante concreta dos marcadores na seleção assistida é durante o processo de piramidação de alelos de resistência. Essa é uma estratégia que vem sendo considerada como uma forma de desenvolver cultivares com resistência duradoura e de amplo espectro. No entanto, na prática, é um processo extremamente difícil e trabalhoso, principalmente pela dificuldade em se identificar, de modo preciso, os sintomas de resistência após múltiplas inoculações. Marcadores moleculares ligados aos alelos a serem piramidados podem ser monitorados ao longo do processo de piramidação, constituindo-se em ferramenta de seleção indireta, evitando as dificuldades inerentes ao processo de seleção via análise de sintomas.

$\mathrm{O}$ uso de retrocruzamentos permite reduzir o arraste de genes ("linkage drag") indesejáveis durante o processo de transferência de alelos de resistência a partir de material genético exótico. $\mathrm{O}$ uso concomitante de marcadores moleculares, particularmente daqueles que flanqueiam o alelo de resistência, pode diminuir consideravelmente esse efeito.

Finalmente, os marcadores moleculares podem ser usados no processo de retrocruzamento para facilitar/acelerar a recuperação do genoma do genitor recorrente. Neste caso, é definido um "fingerprint" molecular do recorrente e este é comparado com aqueles obtidos das linhagens criadas ao longo do processo de melhoramento. Somente aquelas linhagens que carregam o alelo de resistência e que possuam um "fingerprint" semelhante ao do genitor recorrente são utilizadas nos próximos ciclos de retrocruzamento.

\section{MARCADORES MOLECULARES DO DNA}

Marcadores do DNA foram inicialmente utilizados no melhoramento de plantas no início da década de 80 (Soller \& Beckmann, 1983). Resumidamente, são segmentos de DNA que estão fisicamente ligados a locos que determinam características de interesse. Podem ser evidenciados por métodos que combinam o uso de enzimas de restrição à hibridização entre seqüências complementares de DNA, como no caso do "Restriction Fragment Length Polymorphisms" (RFLP) ou pela técnica de "Polymerase Chain Reaction" (PCR). O grande potencial do uso de marcadores moleculares no melhoramento reside no fato de eles serem praticamente ilimitados em número, de fácil detecção e se comportarem como "caracteres" de herança simples e previsível, não sendo afetados pelo meio.

\section{Tipos de marcadores moleculares}

O primeiro tipo de marcador do DNA utilizado no melhoramento de plantas foi o RFLP (Helentjaris et al., 1986). Nessa técnica, o DNA total de um indivíduo é inicialmente isolado e clivado com enzimas de restrição. Os fragmentos obtidos são separados por eletroforese e transferidos para uma membrana de celulose ou náilon. Em seguida, fragmentos específicos podem ser detectados pela incubação da membrana com uma sonda previamente marcada (radioativamente ou a frio). Sonda é uma seqüência de DNA (normalmente da própria espécie em estudo) que irá, por complementaridade entre as bases nitrogenadas, parear com um ou mais dos fragmentos contidos na membrana. A posição da membrana onde a sonda hibridiza pode ser determinada por autorradiografia. O polimorfismo entre diferentes indivíduos decorre de variações nas seqüências primárias dos sítios de restrição ou na mudança de suas posições devido a inserções e/ou deleções. As dificuldades inerentes à técnica, o grande número de etapas e o uso, em muitos casos, de sondas radioativas, impedem que o RFLP seja extensivamente utilizado no melhoramento. 
O "Random Amplified Polymorphic DNA" (RAPD) é uma técnica que utiliza a reação de PCR para detectar fragmentos específicos de DNA (Williams et al., 1990). Ao contrário do PCR convencional, o RAPD utiliza apenas um "primer" curto (cerca de dez nucleotídeos) que, devido ao seu pequeno tamanho, pode parear em diversos pontos do genoma. Caso duas cópias desse "primer" se liguem às fitas opostas do DNA, a uma distância entre 200 e cerca de 2.000 pares de nucleotídeos, pela reação de PCR, a região flanqueada pelos "primers" pode ser amplificada. Portanto, é uma técnica que não exige o conhecimento prévio da seqüência que está sendo amplificada, ao contrário do PCR convencional. Logo, um mesmo conjunto de "primers" pode ser usado para amplificar o DNA dos mais diversos tipos de organismos. Há empresas que comercializam kits de "primers" contendo mais de 1.000 diferentes tipos de seqüência. Apesar de todas essas vantagens, o RAPD apresenta uma desvantagem que limita, até certo ponto, o seu uso generalizado. A baixa temperatura necessária para a ligação do "primer" ao molde torna o processo bastante dependente das condições de amplificação. Portanto, modificações no termociclador utilizado, na DNA polimerase e em outros reagentes da mistura de reação podem alterar o padrão de amplificação. Isto pode não representar um grande problema em um grupo de pesquisadores cuidadosos e que padronizam criteriosamente as condições de amplificação, mas pode impedir que dados sejam comparados entre diferentes laboratórios. Para contornar essa limitação, marcadores RAPD podem ser transformados em marcadores "Sequence Characterized Amplified Regions" (SCAR). Neste caso, a banda de DNA correspondente ao marcador RAPD é clonada, seqüenciada e dois "primers" mais longos que o original são sintetizados e utilizados para amplificar o mesmo marcador, só que agora numa temperatura de anelamento mais elevada. Nessa condição, o processo de amplificação é mais estável e reprodutível (Paran \& Michelmore, 1993).

O polimorfismo evidenciado pelo RAPD é detectado em função de mutações no(s) sítio(s) de ligação do "primer", que impedem o seu pareamento e a conseqüente amplificação, ou devido à ocorrência de deleções ou inserções na região compreendida entre os dois sítios, que alteram o tamanho do segmento amplificado. Como, na maioria das vezes, essas mutações impedem a amplificação do segmento de interesse, diz-se que a herança do RAPD é dominante, pois apenas duas classes fenotípicas serão detectadas, presença ou ausência da banda de DNA.

Marcadores microssatélites ou seqüências simples repetidas (SSR) têm sido preferidos a outros tipos de marcadores, pois utilizam a agilidade da técnica de PCR, são codominantes e estão espalhados ao acaso no genoma com uma freqüência relativamente alta (Akkaya et al., 1992). Essas seqüências são constituídas de repetições de um a seis nucleotídeos que ocorrem naturalmente no genoma. Devido a erros que podem ocorrer durante a replicação do DNA, diferentes indivíduos de uma mesma espécie podem apresentar um número variado de repetições dentro de um mesmo microssatélite, os quais constituem diferentes alelos. Para que o microssatélite seja útil como marcador, ele deve ser inicialmente clonado, seqüenciado e amplificado a partir de "primers" que o flanqueiem. Em seguida, os produtos de amplificação são separados por eletroforese e visualizados. $\mathrm{Na}$ maioria das vezes, a eletroforese deve ser feita em gel de poliacrilamida devido à pequena diferença de tamanho entre os fragmentos alélicos.

"Amplified Fragment Length Polymorphisms" (AFLP) é uma técnica que combina a clivagem de fragmentos de DNA com enzimas de restrição e a amplificação desses fragmentos por PCR (Vos et al., 1995). Resumidamente, nessa técnica, o DNA de um indivíduo é clivado com enzimas de restrição, às suas extremidades são ligados adaptadores, os quais servem de sítios de ligação para "primers" numa reação de PCR. Apesar de ser um tipo de marcador bastante útil para a realização de "fingerprints" de DNA, principalmente quando existem poucas informações disponíveis a respeito do genoma de interesse, o seu uso no melhoramento de plantas tem sido limitado devido a dificuldades metodológicas inerentes à técnica e ao seu elevado custo.

\section{Correlacionando marcador e loco de interesse}

Uma das etapas mais importantes no uso de marcadores moleculares é o estabelecimento da relação entre um dado marcador e um loco de interesse. É uma etapa trabalhosa que exige bastante critério e, até mesmo, um pouco de sorte. Devido ao fenômeno de recombinação, as regiões que circunvizinham o loco de interesse podem ser distintas, mesmo entre materiais genéticos aparentados. Portanto, um marcador polimórfico entre os progenitores $\mathrm{A}$ e $\mathrm{B}$, pode não ser polimórfico entre A e C. Logo, para cada cruzamento, marcadores específicos devem ser identificados. Em muitos casos, no entanto, um mesmo marcador pode ser útil em diferentes populações derivadas de diferentes cruzamentos.

$\mathrm{O}$ primeiro requisito para a identificação de um marcador é a disponibilidade de uma população segregante para a característica de interesse. Pode ser uma população $\mathrm{F}_{2}$, uma população derivada de retrocruzamento ou mesmo uma população de linhagens endogâmicas recombinantes (RILs). A correlação entre o marcador e o loco de interesse pode ser obtida por meio da técnica de "bulks" segregantes ou BSA (Michelmore et al., 1991) ou pela construção de um mapa de ligação (Paterson, 1998). Para caracteres qualitativos é comum o uso da técnica de BSA. Nessa técnica, indivíduos contrastantes para a característica de interesse, pertencentes a uma população segregante (geralmente uma $\mathrm{F}_{2}$ ), são agrupados em dois "bulks" e o seu DNA é analisado quanto à presença de polimorfismos. O agrupamento dos indivíduos, teoricamente, iguala o "background" genético dos dois "bulks", com exceção daqueles locos envolvidos com o caráter de interesse e, por conseguinte, os marcadores a eles associados. Logo, um eventual polimorfismo entre os dois "bulks" tem uma forte probabilidade de estar associado ao(s) alelo(s) que governa(m) o caráter de interesse. 
A associação entre marcadores moleculares e locos para caracteres quantitativos "quantitative trait loci” (QTLs) pode ser evidenciada, de modo mais preciso, por meio de mapas de ligação saturados (Paterson, 1998). Uma população segregante para o caráter de interesse é utilizada para a construção de um mapa de ligação com marcadores moleculares distantes entre si cerca de 5 centiMorgans, por exemplo. Cada indivíduo da população segregante é analisado fenotipicamente e, em seguida, por análise de regressão é possível estabelecer a relação entre marcadores moleculares e os QTLs que afetam a expressão do caráter de interesse. Um mapa saturado permite a identificação de um intervalo delimitado por marcadores e contendo o QTL. Esse QTL pode, então, ser monitorado pela seleção dos marcadores que o flanqueiam.

\section{PIRAMIDAÇÃO DE GENES DE RESISTÊNCIA NO FEIJOEIRO - UM EXEMPLO CONCRETO DO USO DA S.A.M.}

As seguintes etapas são fundamentais no desenvolvimento de um programa de "Piramidação de genes de resistência auxiliado por marcadores moleculares": (1) seleção de genitores contrastantes para genes de resistência às doenças de interesse e identificação das raças do patógeno de maior importância para a região para a qual se destinam as novas variedades, (2) estudos de herança da resistência às raças selecionadas a partir de cruzamentos entre as fontes de resistência e a cultivar suscetível de interesse, (3) identificação de marcadores moleculares ligados aos diferentes alelos de resistência, e (4) desenvolvimento de isolinhas por meio de retrocruzamentos. As isolinhas obtidas por S.A.M. e que possuam os marcadores de interesse serão os materiais utilizados na piramidação de alelos de resistência.

O Programa de Melhoramento do Feijoeiro do Instituto de Biotecnologia Aplicada à Agropecuária (BIOAGRO) da Universidade Federal de Viçosa (UFV), que tem como um dos objetivos a piramidação de genes de resistência à antracnose, ferrugem e a mancha-angular, causadas pelos fungos Colletotrichum lindemuthianum (Sacc. e Magn.) Scrib., $U$. appendiculatus e Phaeoisariopsis griseola (Sacc.) Ferraris, respectivamente, em cultivares de feijoeiro com grãos do tipo carioca, utiliza as cultivares TO, AB 136, G 2333, PI 207.262, Ouro Negro, AND 277, Mexico 54, MAR 2 e Cornell 49242 como fontes de resistência (Tabela 1). Em conjunto, essas fontes conferem resistência a todas as raças de $C$. lindemuthianum, $U$. appendiculatus e $P$. griseola (exceto raça 63.63) identificados no Brasil (Rava et al., 1994; Faleiro et al., 1999; Nietsche et al., 2001). O genitor recorrente usado é a cultivar comercial Rudá (Mesoamericano) desenvolvida pelo Centro Internacional de Agricultura Tropical e recomendada pela EMBRAPA - Arroz e Feijão. Esta cultivar, além de possuir grãos do tipo carioca, é altamente produtiva, bem aceita por uma extensa faixa da população brasileira, mas suscetível à maioria das raças de $C$. lindemuthianum, $P$. griseola e U. appendiculatus.
Inicialmente, foram realizados estudos de herança em populações $\mathrm{F}_{2}$ derivadas de cruzamentos entre as fontes de resistência e a cultivar Rudá. Ficou evidenciado que em quase todos os cruzamentos realizados um só alelo de caráter dominante foi responsável pela resistência. Somente as populações provenientes dos cruzamentos com G 2333 e PI 207.262 mostraram uma segregação de 15:1 (Tabela 1). Dois genes independentes determinam resistência às raças $73 \mathrm{e}$ 89 de C. lindemuthianum nas cultivares G 2333 e PI 207.262. Paralelamente, usando estas mesmas populações $F_{2}, 15$ marcadores moleculares do tipo RAPD foram identificados como ligados em fase de acoplamento aos alelos de resistência. Alguns desses marcadores RAPD foram clonados, sequenciados e transformados em marcadores SCAR que são amplificados de modo mais reprodutível que os marcadores RAPD.

O método de melhoramento utilizado pelo Programa do BIOAGRO/UFV para a piramidação dos genes de resistência é o dos retrocruzamentos. Esse método têm sido largamente utilizado para a transferência de características simples, geralmente controladas por um único gene, para cultivares elite. Por esse método, a proporção esperada do genoma do parental doador é reduzida pela metade em cada geração de retrocruzamento e, após seis retrocruzamentos, a recuperação do genoma do genitor recorrente (GR) é maior que $99 \%$, calculada pela fórmula: $\% \mathrm{GR}=100\left[1-(0,5)^{\mathrm{n}+1}\right]$, onde $\mathrm{n}$ é o número de retrocruzamentos (Fehr, 1987).

A utilização de marcadores moleculares para a identificação de indivíduos com maior proporção do genoma recorrente permitiu reduzir o número de retrocruzamentos requeridos para recuperar o genoma do mesmo (Alzate-Marin et al., 1999; Faleiro et al., 2001). Até o momento, foram piramidados no genitor recorrente Rudá os alelos independentes de resistência Co-4 e Co-6 a C. lindemuthianum procedentes das cultivares $\mathrm{TO}$ e $\mathrm{AB} 136$, respectivamente, os alelos de resistência à antracnose $(\mathrm{Co}-10)$ e ferrugem ( $\mathrm{Ur}$ ?) que estão ligados entre si na cultivar Ouro Negro e o alelo de resistência à mancha-angular da cultivar AND 277 ( $P h g$ 1). Como o alelo de resistência à antracnose da cultivar Ouro Negro era desconhecido, esta cultivar foi submetida a um amplo estudo de alelismo, que levou à sua identificação como Co-10 (Alzate-Marin et al., 2003).

A Figura 1 mostra, em termos gerais, o processo seguido durante o programa de introgressão de genes de resistência na cultivar carioca Rudá seguindo a metodologia de retrocruzamentos assistidos por marcadores moleculares (S.A.M.)".

Seguindo esta metodologia foi possível obter, em três gerações de retrocruzamento, isolinhas com características fenotípicas e genotípicas altamente similares às da cultivar recorrente Rudá, possuindo os alelos independentes de resistência derivados das cultivares AB 136 ( $\mathrm{Co}-6)$, TO ( $\mathrm{Co}$ 4), Ouro Negro (Co-10 e Ur-?) e AND 277 (Phg-1). Após este processo cada linhagem foi autofecundada para a obtenção de populações $\mathrm{F}_{3} \mathrm{RC}_{3}$ e posterior seleção de isolinhas homozigotas para os alelos de resistência. Para maximizar a 
Seleção assistida por marcadores moleculares visando ao desenvolvimento de...

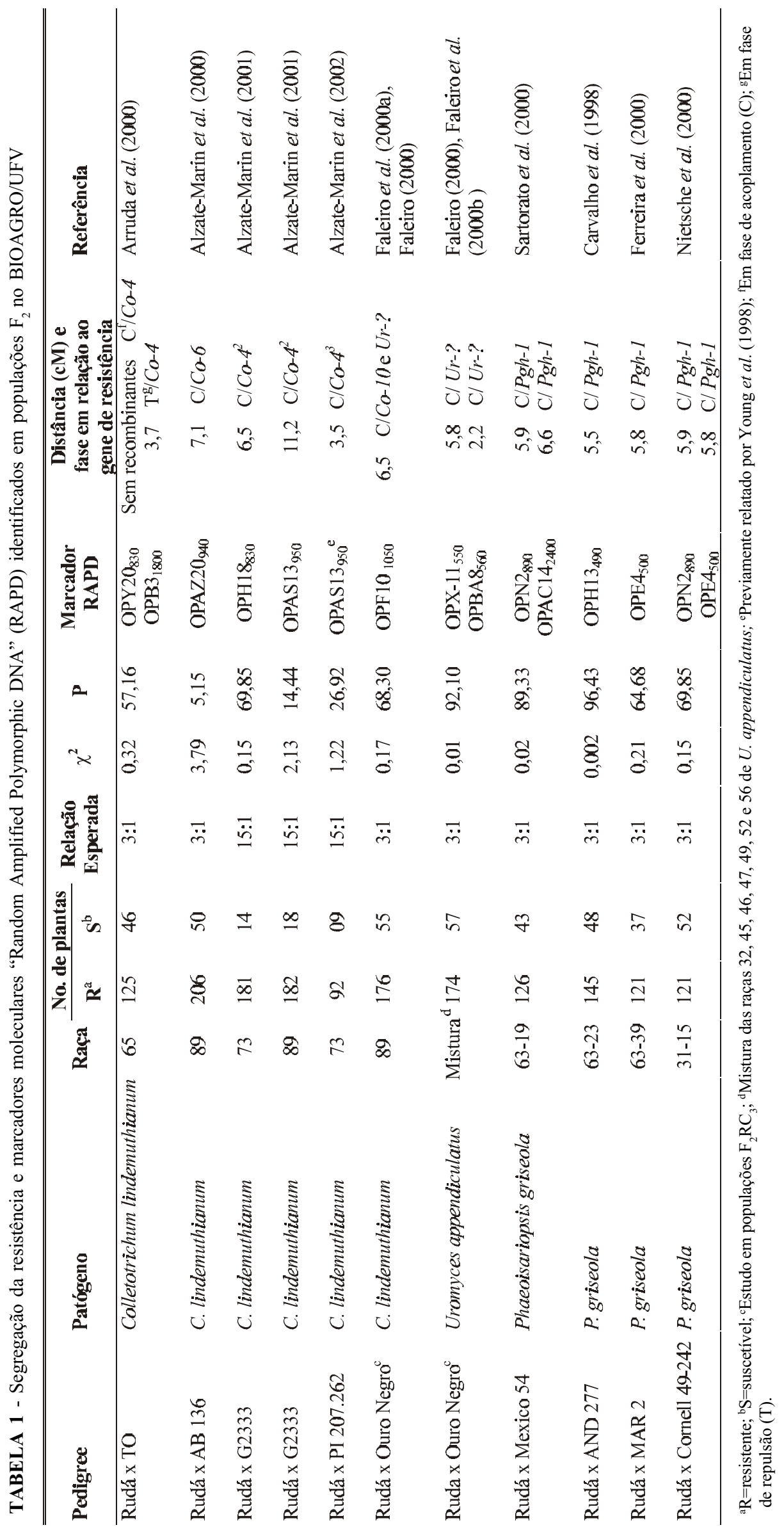




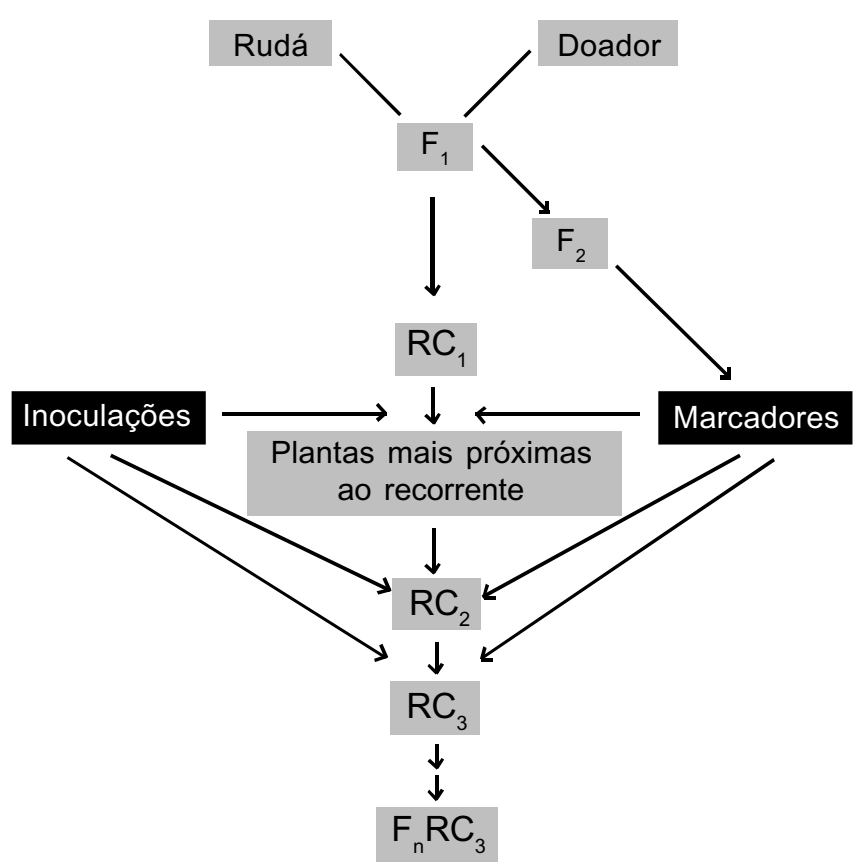

FIG. 1 - Esquema dos retrocruzamentos visando a obtenção de isolinhas homozigotas de feijoeiro (Phaseolus vulgaris) para resistência à antracnose, ferrugem e mancha-angular.

eficiência do programa, marcadores moleculares do tipo RAPD foram empregados novamente na seleção de isolinhas homozigotas resistentes mais próximas do progenitor recorrente. As linhagens obtidas foram avaliadas quanto à reação de resistência a dez, 18 e seis diferentes raças de $U$. appendiculatus, C. lindemuthianum e $P$. griseola, respectivamente (Ragagnin, 2001). Com base nesses resultados, foram selecionadas as isolinhas de maior espectro de resistência para serem intercruzadas e seus alelos de resistência piramidados numa só cultivar com o auxílio dos marcadores moleculares identificados previamente (Tabela 1).

Os intercruzamentos foram realizados entre linhagens homozigotas contendo separadamente o alelo $\mathrm{Co}-4 \mathrm{e}$ o alelo Phg- 1 e linhagens contendo o alelo Co-6 e os alelos $U r$-? e Co-10. As plantas $\mathrm{F}_{1}$ obtidas foram intercruzadas para gerar indivíduos contendo alelos de resistência dos cinco genes de interesse. Esse processo foi acompanhado por seleção indireta com os marcadores para cada um dos genes envolvidos. As plantas contendo os cinco alelos de resistência foram, então, autofecundadas até a geração $\mathrm{F}_{4}$. Neste momento, sementes das linhagens $\mathrm{F}_{4}$, homozigotas para os cinco locos de resistência (Co-4Co-4Co-6Co-6Co-10Co-10Phg-1Phg- $1 \mathrm{Ur}$ ?Ur-?), estão sendo multiplicadas para serem submetidas a inoculações com os patógenos de interesse e a testes agronômicos.

Para dar continuidade aos programas de melhoramento que empregam a S.A.M. como ferramenta auxiliar, deve-se considerar como atividades prioritárias e de rotina, (1) a caracterização contínua da variabilidade genética dos patógenos e do hospedeiro, (2) a introdução e caracterização de novas fontes de resistência, e (3) a identificação de marcadores moleculares ligados a alelos de resistência. Este tipo de estratégia poderia ser conduzida de maneira integrada entre as Instituições Estaduais e Federais de Ensino/Pesquisa do País.

\section{DESENVOLVIMENTO DE CULTIVARES DE SOJA [Glycine max (L.) Merrill] RESISTENTES AO NEMATÓIDE DE CISTO}

Na década de 70, a expansão do cultivo da soja para o Brasil Central levou a um grande incremento na produção dessa cultura no país. A expansão da área cultivada foi acompanhada pelo incremento na produtividade, de forma constante. Esse fato foi devido a mudanças de práticas culturais, uso de agro-químicos, de forma geral, que minimizaram o estresse abiótico e biótico, ajudando a superar a performance das cultivares de soja, e ao melhoramento genético. Atualmente, ganhos na produtividade como resultado apenas de melhoras do ambiente podem ser limitados, principalmente em regiões onde a agricultura é praticada com uso de tecnologias avançadas. Portanto, no futuro, esses ganhos dependerão, principalmente, das melhorias genéticas. Assim, melhoristas precisam desenvolver e aplicar novas metodologias, visando obter maior eficiência e rapidez no desenvolvimento de cultivares potencialmente mais produtivas.

Nos últimos anos, a soja tem sido alvo de grandes esforços na área do melhoramento, sendo a resistência a doenças um objetivo prioritário. Segundo Yorinori et al. (1993), cerca de 35 patógenos atacam a soja no Brasil, sendo Heterodera glycines Ichinohe ou Nematóide de Cisto da Soja (NCS) um dos principais fatores que limitam a produção dessa cultura.

\section{O nematóide de cisto da soja e ferramentas para seu controle}

O NCS foi primeiramente detectado no Brasil na safra de 1991/92 (Lordello et al., 1992). Atualmente, estima-se que mais de 2 milhões de hectares estejam infetados com esse parasita. A importância dessa enfermidade reside não só no seu efeito negativo sobre a produção, mas também na impossibilidade prática de se erradicar o NCS do solo. O NCS consegue sobreviver sob condições adversas, por meio da formação de cistos, o que torna a sua disseminação extremamente eficiente, pois esta ocorre por qualquer meio de dispersão de solo (Yorinori et al., 1994). Apesar da existência de nematicidas e do controle biológico, a forma mais prática, eficiente e econômica de controle da doença é a rotação de culturas (Epps \& Chambers, 1965). Também a utilização de cultivares resistentes constitui-se numa das formas mais úteis de controle do NCS. Nos Estados Unidos, Annand et al. (1994) catalogaram 130 cultivares resistentes a diferentes raças do NCS. Porém, nenhum é adaptado para o plantio comercial no Brasil. Além disso, o NCS possui grande variabilidade genética e as principais cultivares de 
soja usados no Brasil são suscetíveis. Portanto, programas de melhoramento visando transferir alelos de resistência ao NCS para cultivares comerciais de soja já foram iniciados no Brasil em várias instituições que se dedicam ao melhoramento da soja, tais como o BIOAGRO/UFV e a EMBRAPA-Soja, dentre outras.

A transferência de alelos de resistência é realizada, normalmente, por meio do método dos retrocruzamentos. Embora esse método seja o mais aconselhável, o monitoramento dos genes de interesse, por meio de seleção fenotípica, é trabalhoso e demorado, uma vez que envolve a identificação de raças, inoculação das progênies e avaliação do nível de dano nas linhagens que compõem o programa de melhoramento, especialmente quando o objetivo do programa é a piramidação de alelos de resistência a diferentes raças.

Em soja, como em outras culturas, marcadores moleculares de DNA vêm sendo usados com sucesso tanto no mapeamento de regiões genômicas associadas a QTLs, como é o caso da resistência ao NCS, quanto na seleção de genótipos portadores desses QTLs. Os marcadores moleculares mais usados no melhoramento da soja tem sido o RAPD e os microssatélites. Ambos são marcadores extremamente práticos, simples e requererem pequena quantidade de DNA, permitindo que dezenas de plantas sejam analisadas de uma só vez.

\section{Base genética da resistência ao NCS}

A resistência genética ao NCS foi identificada pela primeira vez por Ross \& Brim (1957), sendo sua herança relatada por Caldwell et al. (1960) na cultivar Peking como controlada por três alelos recessivos independentes ( $\mathrm{h} g \mathrm{l}$, rhg2 e rhg3). Posteriormente, Matson \& Williams (1965) identificaram um alelo dominante (Rhg4) ligado ao loco I, responsável pela cor preta uniforme da semente de soja, como necessário para a resistência, além dos três recessivos previamente encontrados.

Embora os estudos de genética clássica tenham tido sucesso na identificação das fontes de resistência ao NCS, foram poucos esclarecedores a respeito da base genética da resistência. Esse fato ocorreu devido ao uso de populações geneticamente heterogêneas de NCS na maioria dos estudos de herança já feitos, ao sistema de classificação de plantas suscetíveis e resistentes com base no método de Riggs et al. (1988), e também por ter-se assumido que a resistência era governada por fatores mendelianos simples. Marcadores moleculares do DNA são uma alternativa muito útil nesse tipo de sistema. Com base no mapa integrado de soja gerado por Cregan et al. (1999a), foram localizadas duas regiões principais associadas à resistência ao NCS. Uma no grupo de ligação (GL) A2, e outra no GL G. O gene Rhg4 foi mapeado no GL A2 por Weisemann et al. (1992) no acesso PI 209332, por Webb et al. (1995), no acesso PI 437654, em ambos os trabalhos usando marcadores RFLP, e por Mahalingam \& Skorupska (1995) na cultivar Peking, usando marcadores RFLP e RAPD.

Boutin et al. (1992), usando marcadores RFLP, foram os primeiros a detectar um loco de resistência ao NCS no GL G. Nessa mesma região, Concibido et al. (1994) mapearam primeiramente o alelo rhgl que explica mais de $50 \%$ da variação na resistência nas PIs 209332, 90763, 88788 e na cultivar Peking, apresentando dominância parcial nos três últimos genótipos (Concibido et al., 1997). Webb et al. (1995), além do alelo Rhg4 no GL A2, identificaram o rhgl no GL G. A interação entre ambos os genes foi necessária para que a resistência à raça $3 \mathrm{de} \mathrm{NCS}$ fosse completa. Usando marcadores microssatélites, Mudge et al. (1997) concluíram que os microssatélites Satt038 e Satt130 flanqueavam o alelo rhg1. Cregan et al. (1999b) detectaram os SSR Sat_168 e o Satt 309 delimitando o rghl.

A equipe de trabalho de BIOAGRO/UFV, que vêm usando marcadores moleculares com a finalidade de identificar QTLs associados a várias características de interesse agronômico-industrial em soja, têm confirmado a importância do alelo $r h g l$ para a resistência ao NCS. Cervigni (1999), usando população $\mathrm{RC}_{1} \mathrm{~F}_{2}$ proveniente do cruzamento entre Hartwig x Y23 (linhagem brasileira suscetível), identificou o alelo rhgl entre os microssatélites Satt038 e Satt163. Concibido et al. (1997) relataram que o alelo rhgl apresenta resistência parcial. No estudo de Cervingi (1999), o alelo rhgl apresentou dominância quase completa para a resistência $(\mathrm{d} / \mathrm{a}=-0,90)$. Esse dado foi recentemente confirmado por Cervigni (dados não publicados), para as raças $3 \mathrm{e}$ 9, usando uma população de RILs proveniente do cruzamento Hartwig x Y23. A dominância do alelo $r h g 1$ relatada por Cervigni (1999), a sobredominância para a susceptibilidade à raça 4 (Rao-Arelli et al., 1989), a epistasia verificada por Webb et al. (1995), e os efeitos pleiotrópicos relatados por Yue et al. (2001), estudando a resistência às raças 1, 2, 3, 5 e 14 na PI 438489B, demonstram claramente como os efeitos de "background" alteram a interação ente os QTLs de resistência, sejam eles alelos ou não. Nossa equipe, usando marcadores RAPD e SSR, identificou um QTL de resistência à raça 14 no GL D2, usando famílias $\mathrm{RC}_{3} \mathrm{~F}_{2: 3}$ e $\mathrm{F}_{2: 3}$ derivadas do cruzamento Hartwig x BR-39-31983 (Schuster et al., 2001). Esse QTL explica mais de $40 \%$ da resistência em Hartwig, e constitui o único relato associando resistência ao NCS ao GL D2. Yue et al. (2001) também mapearam QTLs de resistência à raça 14, mas foram posicionados nos grupos de ligação GL C1, D1a e E.

A principal finalidade da seleção assistida por marcadores no melhoramento vegetal é auxiliar o melhorista na seleção de genótipos desejáveis, com máxima eficiência, rapidez e com baixo custo. Pela seleção de plantas homozigotas para os microssatélites Satt038 e Satt 163, Cervigni (1999) obteve uma eficiência de seleção (E.S.) para resistência de $91,89 \%$. Este valor é similar àquele informado por Concibido et al. (1996), usando marcadores RFLP. Mudge et al. (1997) relataram que obtiveram uma acurácia na predição da resistência ao NCS de $98 \%$ usando dois microssatélites dominantes. Com base na seleção indireta com marcadores microssatélites, um decréscimo de $70 \%$ no índice de parasitismo foi verificado por Schuster et al. (2001). 
Os valores de E.S. apresentados são semelhantes aos obtidos com os métodos convencionais, em ausência de dominância. Porém, os estudos sobre a base da resistência ao NCS têm mostrado que o número e tipo de ação gênica variam de uma fonte de resistência para outra, bem como o número de genes de resistência presentes nas diferentes fontes. Nesses casos, a seleção fenotípica seria praticamente impossível de se aplicar nas etapas iniciais do programa, o que aumentaria o tempo necessário à fixação dos alelos de resistência. Por outro lado, a seleção praticada com o auxílio de marcadores ligados aos QTLs de resistência, poderia ser feita nas gerações iniciais do programa, com os altos valores de E.S. relatados. A E.S. entre marcadores difere de uma fonte de resistência para outra devido à distância genética relativa dos marcadores ao QTL que flanqueiam. Portanto, deve-se salientar que esses marcadores, antes de serem usados em programas de melhoramento, devem ser validados, isto é, deve-se determinar a eficiência de seleção que eles terão, considerando a fonte de resistência e a raça do NCS para o qual se pretende a resistência.

Para definir uma estratégia de seleção para resistência ao NCS, usando marcadores moleculares, é necessário, primeiramente, definir que tipo de marcador será usado, e se o QTL está flanqueado ou não por marcadores. Maiores valores de E.S. são obtidos com marcadores codominantes flanqueando o QTL a pequenas distâncias $(<10 \mathrm{cM})$. Segundo, os marcadores que são ligados a um QTL, antes de serem usados na S.A.M., devem ter sua E.S. validada. Validar significa inocular a(s) raça(s) em populações com diferentes fontes de resistência, e detectar a presença dos marcadores ligados ao(s) QTL(s). Se o marcador estiver ligado em fase de acoplamento, a soma das plantas resistentes sem a marca e das suscetíveis com a marca dará o erro a ser obtido na seleção. Finalmente, para delinear uma estratégia de piramidação desses QTLs, é preciso saber quantos QTLs serão considerados na seleção, se são independentes ou ligados, e quantos doadores serão usados. Desta forma, temse uma idéia aproximada do tamanho da população de trabalho necessária para a obtenção do genótipo desejado.

\section{OUTROS EXEMPLOS DO USO DE MARCADORES MOLECULARES}

Marcadores moleculares podem ser usados para o desenvolvimento de mapas genéticos de alta resolução (Cregan et al., 1999a). Esses tipos de mapas, além de poderem ser integrados com mapas físicos, tornam factível a clonagem posicional de QTLs de interesse. Mekesem et al. (2000) construíram um mapa de alta saturação de três regiões genômicas em soja, as quais contém os alelos Rhg4 e rhgl, que conferem resistência ao NCS, e a região que contém o alelo $R f_{s}$, que confere resistência a Fusarim solani (Mart.) Sacc. f. sp. glycines, agente causal da síndrome da morte súbita. Uma vez que os alelos de resistência, geralmente, encontram-se agrupados, esta estratégia permitiria a clonagem de alelos de resistência para uma ou várias doenças, que combinados em grandes segmentos de DNA, poderiam ser usados na transformação genética de plantas (Liu et al., 1999).

\section{CONSIDERAÇÕES FINAIS}

O uso de marcadores moleculares do DNA na S.A.M. visando ao desenvolvimento de cultivares resistentes a doenças é uma realidade em diversos programas de melhoramento no mundo inteiro. A S.A.M. é uma metodologia que foi desenvolvida com o avanço da Genética Molecular e que veio somar-se a outros procedimentos utilizados para facilitar o processo de melhoramento. O uso rotineiro dessa metodologia depende do conhecimento dos seus princípios básicos, do estabelecimento de uma infra-estrutura laboratorial mínima que permita a rápida extração de DNA e detecção dos marcadores. No entanto, muito mais do que isso, o seu uso exige uma mudança de filosofia por parte do melhorista, uma mudança que admita a incorporação de uma metodologia avançada, que possa facilitar o processo de melhoramento de um modo geral, e que apesar do seu caráter inovador, não contraria os princípios genéticos já estabelecidos.

O uso da S.A.M. no melhoramento de plantas cria uma oportunidade única para estimular a interação entre instituições públicas e privadas pois o desenvolvimento e a validação de marcadores específicos requer um esforço concentrado. Dependendo do tipo de marcador molecular e dos genitores utilizados, os dados obtidos nessa etapa podem ser transferidos automaticamente entre diferentes programas de melhoramento. No entanto, cada população de melhoramento deve ser trabalhada individualmente. A fase de desenvolvimento e validação dos marcadores necessita de incentivo por parte de órgãos de financiamento para estimular a formação de redes entre diversos grupos de pesquisa que possam colaborar entre si e, dessa maneira, acelerar o processo de criação de novas cultivares de interesse.

\section{REFERÊNCIAS BIBLIOGRÁFICAS}

AKKAYA, M.S., BHAGWAT, A.A. \& CREGAN, P.B. Length polymorphisms of simple sequence repeat DNA in soybean. Genetics 132:1131-1139. 1992.

ALZATE-MARIN, A.L., MENARIM, H., ARRUDA, M.C.C., CHAGAS, J.M., BARROS, E.G. \& MOREIRA, M.A. Backcross assisted by RAPD markers for the introgression of $\mathrm{Co}-4$ and $\mathrm{Co}-6$ anthracnose resistant genes in common bean cultivars. Bean Improvement Cooperative 42:15-16. 1999.

ALZATE-MARIN, A.L., MENARIM, H., CHAGAS, J.M., BARROS, E.G. \& MOREIRA, M.A. Identification of RAPD marker linked to the Co- 6 anthracnose resistant gene in common bean cultivar AB 136. Genetics and Molecular Biology 23:633-637. 2000.

ALZATE-MARIN, A.L., MENARIM, H., BAIA, G.S., PAULA JR., T.J., SOUZA, K.A., COSTA, M.R., BARROS, E.G. \& MOREIRA, M.A. Inheritance of anthracnose resistance in the common bean differential cultivar G 2333 and identification of a new molecular marker linked to the $\mathrm{Co}-4^{2}$ gene. Journal of Phytopathology 149:259- 
Seleção assistida por marcadores moleculares visando ao desenvolvimento de...

264. 2001

ALZATE-MARIN, A.L., SOUZA, K.A., MORAIS, M.G., BARROS, E.G. \& MOREIRA, M.A. Caracterização de genes que determinam resistência à antracnose no cultivar de feijoeiro PI 207.262. Resumos, VII Congresso Nacional de Pesquisa de Feijão, Viçosa, MG. 2002. pp.225-227.

ALZATE-MARIN, A.L., COSTA, M.R., ARRUDA, K.M., BARROS, E.G. \& MOREIRA, M.A. Characterization of the anthracnose resistance gene present in Ouro Negro (Honduras 35) common bean cultivar. Euphytica 133:165-169. 2003.

ANAND, S.C., SHARMA, S.B., RAO-ARELli, A.P. \& WRATHER, J.A. Variation in parasitic potential of Heterodera glycines population. Crop Science 34:1452-1454. 1994.

ARRUDA, M.C.C., ALZATE-MARIN A.L., CHAGAS, J.M., MOREIRA, M.A. \& BARROS, E.G. Identification of RAPD markers linked to the Co-4 resistance gene to Colletotrichum lindemuthianum in common bean. Phytopathology 90:758-761. 2000.

BOUTIN, S.R., ANSARI, H., CONCIBIDO, V., DENNY, R., ORF, J. \& YOUNG, N.D. RFLP analysis of cyst nematode resistance in soybean. Soybean Genetics Newsletter 19: 123-127. 1992.

CALDWELL, B.E., BRIM, C.A. \& ROSS, J.P. Inheritance of resistance to soybean cyst nematode, Heterodera glycines. Agronomy Journal 52:635-636. 1960.

CARVAlHO, G.A., PAULA Jr., T.J., ALZATE-MARIN, A.L., NIETSCHE, S., BARROS, E.G. \& MOREIRA, M.A. Herança da resistência da linhagem AND-277 de feijoeiro-comum à raça 6323 de Phaeoisariopsis griseola e identificação de marcador RAPD ligado ao gene de resistência. Fitopatologia Brasileira 23:482-485. 1998.

CERVIGNI, G.D.L. Mapeamento de genes de resistência à raça 3 do nematóide de cisto da soja (Heterodera glycines Ichinohe). (Tese de Mestrado). Viçosa. Universidade Federal de Viçosa. 1999.

CONCIBIDO, V.C., DENNY, R.L., BOUTIN, S.R., HAUTEA, R., ORF, J.H. \& YOUNG, N.D. DNA marker analysis of loci underlying resistance to soybean cyst nematode (Heterodera glycines Ichinohe). Crop Science 34:240-246. 1994

CONCIBIDO, V.C., DENNY, R.L., LANGE, D.A., ORF, J.H. \& YOUNG, N.D. RFLP mapping and marker-assisted selection of soybean cyst nematode resistance in PI 209332 . Crop Science 36:1643-1650. 1996.

CONCIBIDO, V.C., LANGE, D.A., DENNY, R.L., ORF, J.H., \& YOUNG, N.D. Genome mapping of soybean cyst nematode resistance genes in Peking, PI 90763, and PI 88788 using DNA markers. Crop Science 37:258-264. 1997.

CREGAN, P.B., JARVIK, T., BUSH, A.L., SHOEMAKER, R.C., LARK, K.G., KAHLER, A.L., KAYA, N., VANTOAI, T.T., LOHNES, D.G., CHUNG, J. \& SPECHT J.E. An integrated genetic linkage map of the soybean. Crop Science 39:1464-1490. 1999a.

CREGAN, P.B., MUDGE, J., FICKUS, E.W., DANESH, D., DENNY, R. \& YOUNG, N.D. Two simple sequence repeat markers to select for soybean cyst nematode resistance conditioned by the rhgl locus. Theoretical and Applied Genetics 99:811-818. 1999b. EPPS, J.M. \& CHAMBERS, A.Y. Populations dynamics of Heterodera glycines under various cropping sequences in field binds. Phytopathology 55:100-103. 1965.

FALEIRO, F.G. Melhoramento e Mapeamento Genético do feijoeiro- comum: Análise de características quantitativas, morfologicas, moleculares e de resistência a doenças. (Tese de Doutorado). Viçosa. Universidade Federal de Viçosa. 2000.

FALEIRO, F.G., VINHADELLI, W.S., RAGAGNIN, V.A., ZAMBOLIM, L., PAULA Jr., T.J., MOREIRA, M.A. \& BARROS, E.G. Identificação de raças fisiológicas de Uromyces appendiculatus no estado de Minas Gerais. Fitopatologia Brasileira 24:166-169. 1999.

FALEIRO, F.G., RAGAGNIN, V.A., CORRÊA, R.X., VINHADELLI, W.S., MOREIRA, M.A. \& BARROS, E.G. Ligação gênica da resistência à ferrugem e à antracnose na variedade de feijão Ouro Negro. Revista Ceres 47:375-382. 2000a.

FALEIRO, F.G., VINHADELLI, W.S., RAGAGNIN, V.A., CORREAA, R.X., MOREIRA, M.A., BARROS, E.G. RAPD markers linked to a block of genes confering rust resistance to the common bean. Genetics and Molecular Biology 23:399-402. 2000b.

FALEIRO, F.G., RAGAGNIN, V.A., CARVALHO, G.A., PAULA Jr., T.J., MOREIRA, M.A. \& BARROS, E.G. Development of common bean lines resistant to rust and anthracnose by molecular marker-assisted backcrossing. Bean Improvement Cooperative 44:109-110. 2001.

FEHR, W.R. Principles of Cultivar Development, Vol. 1: Theory and Technique. New York. Macmillan. 1987.

FERREIRA, C.F., BORÉM, A., CARVALHO, G.A., NIETSCHE, S., PAULA Jr., T.J., BARROS, E.G. \& MOREIRA, M.A. Inheritance of angular leaf spot resistance in common bean and identification of a RAPD marker linked to a resistance gene. Crop Science 40:1130-1133. 2000

FLOR, H.H. Current status of gene-for-gene concept. Annual Review of Phytopathology 9:275-296. 1971.

HELENTJARIS, T., SLOCUM, M., WRIGHT, S., SCHAEFER, A. \& NIENHUIS J. Construction of genetic linkage maps in maize and tomato using restriction fragment length polymorphisms. Theoretical and Applied Genetics 72:761-769. 1986.

LIU, Y. G, SHIRANO, Y., FUKAKI, H., YANAI, Y., TASAKA, M., TABATA, S. \& SHIBATA, D. Complementation of plant mutants with large genomic DNA fragments by a transformation-competent artificial chromosome vector accelerates positional cloning. Proceedings of the National Academy of Science USA 96:65356540. 1999

LORDELlO, A.I.L., LORDELLO, R.R.A. \& QUAGGIO, J.A. Ocorrência do nematóide de cisto da soja (Heterodera glycines) no Brasil. Revista Agricultura 67:223-225. 1992.

MAHALINGAM, R. \& SKORUPSKA, H.T. DNA markers for resistance to Heterodera glycines Race 3 in soybean cultivar Peking. Breeding Science 45:435-443. 1995.

MATSON, A.L. \& WILLIAMS, L.F. Evidence of four genes for resistance to the soybean cyst nematode. Crop Science 22:588-590. 1965.

MEKSEM , K., ZOBRIST, K., RUBEN, E., HYTEN, D., QUANZHOU, T., ZHANG, H. B. \& LIGHTFOOT, D.A. Two largeinsert soybean genomic libraries constructed in a binary vector: application in chromosome walking and genome wide physical mapping. Theoretical and Applied Genetics 101:747-755. 2000.

MICHELMORE, R.W., PARAN, I. \& KESELLI, V. Identification of markers linked to disease-resistance genes by bulked segregant analysis: a rapid method to detect markers in specific genomic 
regions by using segregating populations. Proceedings of the National Academy of Science USA 88:9828-9832. 1991. MUDGE, J., CREGAN, P.B., KENWORTHY, J.P., KENWORTHY, W.J., ORF, J.H. \& YOUNG, N.D. Two microsatellite markers that flank the major soybean cyst nematode resistance locus. Crop Science 37:1611-1615. 1997.

NIETSCHE, S., BORÉM, A., CARVALHO, G.A., ROCHA, R.C., PAULA Jr., T.J., BARROS, E.G. \& MOREIRA, M.A. RAPD and SCAR markers linked to a gene conferring resistance to angular leaf spot in common bean. Journal of Phytopathology 148:117-122. 2000. NIETSCHE, S., BOREM, A., CARVALHO, G.A., PAULA Jr., T.J., FERREIRA, C.F., BARROS, E.G. \& MOREIRA, M.A. Genetic diversity of Phaeoisariopsis griseola in the state of Minas Gerais. Euphytica 117:77-84. 2001.

PARAN, I. \& MICHELMORE, R.W. Development of reliable PCR based markers linked to downy mildew resistance genes in lettuce. Theoretical and Applied Genetics 85:985-993. 1993.

PATERSON, A.H. Of blending, beans, and bristles: the foundations of QTL mapping. In: Paterson, A.H. (Ed.) Molecular Dissection of Complex Traits. New York. CRC Press. 1998. pp.1-10.

RAGAGNIN, V.A. Seleção, Caracterização e Comportamento de isolinhas de feijoeiro-comum resistentes à ferrugem, antracnose e mancha angular. (Dissertação, Mestrado em Genética e Melhoramento), Universidade Federal de Viçosa, Viçosa, MG. 2001.

RAO-ARELLI, A.P., ANAND, S.C. \& MYERS, G.O. Partial dominance of susceptibility in soybean to soybean cyst nematode races 3, 4 and 5. Crop Science 29:562-1564. 1989.

RAVA, C.A., PURCHIO, A. \& SARTORATO, A. Caracterização de patótipos de Colletotrichum lindemuthianum que ocorrem em algumas regiões produtoras de feijoeiro comum. Fitopatologia Brasileira 19:167-172. 1994.

RICK, C.M. \& FOBES, J.S. Association of an allozyme with nematode resistance. Report of the Tomato Genetics Cooperative 24:25. 1974

RIGGS, R.D., SCHMIDT, D.P. \& NOEL, G.R. Variability in race tests with Heterodera glycines. Journal of Nematology 20:565-572. 1988.

ROSS, J.P. \& BRIM, C.A. Resistance of soybean to the soybeancyst nematode as determined by a double-row method. Plant Disease Report 41:923-924. 1957.

SARTORATO, A., NIETSCHE, S., BARROS, E.G. \& MOREIRA,
M.A. RAPD and SCAR markers linked to resistance gene to angular leaf spot in common beans. Fitopatologia Brasileira 25:637-642. 2000.

SCHUSTER, I., ABDELNOOR, R.V., MARIN, S.R.R., CARVALHO, V.P., KIIHL, R.A.S., SILVA, J.F.V., SEDIYAMA, C.S., BARROS, E.G. \& MOREIRA, M.A. Identification of a new QTL associated with resistance to soybean cyst nematode (Heterodera glycines). Theoretical and Applied Genetics 102:9196. 2001.

SOLLER, M. \& BECKMANN, J.S. Genetic polymorphism in varietal identification and genetic improvement. Theoretical Applied Genetics 67:25-33. 1983.

VOS, P., HOGERS, R., BLEEKER, M., REIJANS, M., VAN DE LEE, T., HORNES, M., FRIJTERS, A., POT, J., PELEMAN, J., KUIPER, M. \& ZABEAU, M. AFLP: A new technique for DNA fingerprinting. Nucleic Acids Research 23:4407-4414. 1995.

WEBB, D. M., BALTAZAR, B. M., RAO-ARELLI, A.P., SCHUPP, J., CLAYTON, K., KEIM, P. \& BEAVIS, W. D. Genetics mapping of soybean cyst nematode race-3 resistance loci in the soybean PI 437.654. Theoretical and Applied Genetics 91:574-581. 1995.

WEISEMANN, J.M., MATTHEWS, B.S. \& DEVINE, T.E. Molecular markers located to the soybean cyst nematode resistance gene, Rhg4. Theoretical and Applied Genetics 85:136-138. 1992.

WILLIAMS, J., KUBELIK, A., LIVAK, K., RAFALSKI, A. \& TINGEY, S. DNA polymorphism amplified by arbitrary primers are useful as genetic markers. Nucleic Acids Research 18:65316535. 1990.

YORINORI, J.T., CHARCHAR, M.J.D., NASSER, L.C.B. \& HENNING, A.A. Doenças da soja e seu controle. In: Arantes, N.E. \& Souza, P.I.M. (Eds.) Cultura de Soja nos Cerrados. Piracicaba, SP. Potafos. 1993. pp.333-397.

YORINORI, J.T., GALERANI, P.R. \& GARCIA, A. Manejo da cultura para controle do nematóide de cisto da soja. EMBRAPACNPSo, Documento, 83. 1994.

YOUNG, R., MELOTTO, M., NODARI R.O. \& KELLY J.D. Marker-assisted dissection of the oligogenic anthracnose resistance in the common bean cultivar, "G2333". Theoretical and Applied Genetics 96:87-94. 1998.

YUE, P., ARELLI, P.R. \& SLEPER, D.A. Molecular characterization of resistance to Heterodera glycines in soybean PI 438489B. Theoretical and Applied Genetics 102:921-928. 2001. 